\title{
ETHERNET-BASED MONITORING SYSTEMS FOR RENEWABLE ENERGY-HYDROGEN MICROGRIDS
}

Antonio José Calderón Godoy, Isaías González Pérez, José María Portalo Calero, Manuel Calderón Godoy

Escuela de Ingenierías Industriales, Universidad de Extremadura, \{ajcalde, igonzp, calgodoy\}@ unex.es

\begin{abstract}
The digitization of power systems has given birth to the rise of challenging scenarios like Smart Grids and Smart Microgrids. These infrastructures are mainly based in decentralized energy generation as well as in the intelligent management of the energy flows and data communications. For their successful implementation, a communication network is imposed for the proper data transmission between the vast amount of sensors, controllers and supervisory nodes involved. Ethernet-based networks have become the prevalent means for communications in office environments and are being increasingly applied also for industrial facilities. Consequently, Smart Grids and Smart Microgrids are also being equipped with Ethernet communication. This paper presents an Ethernetbased monitoring system architecture where monitoring software, proprietary automation hardware and open-source equipment share data over an Ethernet network. A set of experimental facilities are reported in order to prove the validity of the proposal.
\end{abstract}

Keywords: Renewable energy, microgrid, Ethernet, automation, monitoring, communication network, IoT.

\section{INTRODUCTION}

The digitization of power systems involves the massive introduction of sensing and automation technologies causing the evolution towards the socalled Smart Grids and Smart Microgrids. The future energetic scenario is envisioned to be supported by these intelligent grids with enhanced capabilities of decentralized generation, optimized efficiency and higher introduction of renewable energy sources. Microgrids integrate both physical elements in the power grid and cyber elements (sensor networks, communication networks, and computation core) to make the power grid operation effective [21].

Apart from the energy flows, information flows characterize these grids [22]. Consequently, proper information management and transmission networks are required between the vast amount of sensors, controllers and supervisory nodes involved. Indeed, the implementation of distributed monitoring and control systems is signalled as one of the main challenges in the Smart Grid scenario [4].

In this sense, Ethernet is a widely applied standard for networked communications. Namely, Ethernet corresponds to the IEEE standard 802.3 [15]. Within the Open Systems Interconnection (OSI) model, Ethernet operates in the two lower layers, the physical level (layer 1) and the link level (layer 2). The Transmission Control Protocol/Internet Protocol (TCP/IP) is commonly deployed for Ethernet-based communications. Such a combination provides important building blocks to achieve technical interoperability between disparate digital systems [19].

Ethernet provides high bandwidth, scalability and modular configuration with inexpensive expenditures. Moreover, in the context of R\&D projects, the application of Ethernet communication fosters an enhanced management of interoperability and flexibility. Both benefits acquire special relevance when a variety of heterogeneous equipment must be integrated and/or modified.

In fact, Ethernet is becoming a de facto standard in office, enterprise or business systems and modern Cyber-Physical Systems (CPS) [19]. Indeed, the undeniable prevalence of Ethernet networks contributes to the trend of industrial networks towards such communication means. Both proprietary and open communication protocols widely used in industrial environment have released specifications for Ethernet. Fieldbuses like Modbus TCP, PROcess FIeld NETwork (PROFINET), Ethernet for Control Automation (EtherCAT) or CCLink IE are examples of such trend.

Another remarkable aspect concerning industrial control equipment is the application of Programmable Logic Controllers (PLC) to automate renewable energy facilities and microgrids in literature $[3,8,9,16]$. Modern PLC include Ethernet 
ports for easy connection to Local Area Networks (LAN) and even to be accessible from remote locations via Internet.

In the market, a common feature of commercial equipment for energy purposes is Ethernet connectivity. For instance, manufacturers like Victron Energy [14] or SMA [13] sell inverters, solar chargers and associated devices with embedded Ethernet port.

Moreover, open-source Internet-of-Things (IoT) technologies are also being applied for sensing and monitoring purposes in energy facilities. The most widespread examples of this kind of technology are the microcontroller Arduino [2, 10] and the microcomputer Raspberry Pi (RPi) [12]. Recent publications in this sense can be found in $[5,6,7,9$, $17,18,20]$.

This paper presents an Ethernet-based monitoring system architecture which integrates monitoring software, proprietary automation hardware and opensource equipment. A set of experimental applications in microgrids are reported to prove the validity of the proposal. The motivation for this work arises during the design and implementation of the monitoring and automation systems of renewable energy-hydrogen microgrids in the context of $\mathrm{R} \& \mathrm{D}$ projects.

The structure of the rest of the contribution is as follows. The second section presents an Ethernetbased monitoring system architecture. In the third chapter, three experimental application of the proposal in R\&D activities concerning renewable energy-hydrogen microgrids are reported. Finally, the key conclusions are addressed.

\section{ARCHITECTURE ETHERNET-BASED MONITORING SYSTEMS}

OF

A general architecture for monitoring systems supported by Ethernet communication is presented in order to be applicable to modern facilities which include traditional automation units (PLC) as well as open-source IoT devices (RPi, Arduino, etc.). The block diagram of this proposal is depicted in Figure 1 .

As it is illustrated, an Ethernet network acts as backbone for data exchange between the involved nodes. On the one hand, the monitoring system is responsible of gathering operational data from the connected devices and displaying the relevant information to the user. Such information is fed in real-time with both numerical and graphical representations so the user is able to track the current status and operation of the microgrid. In addition, tasks like alarm generation and data accumulation are also performed by the monitoring system.

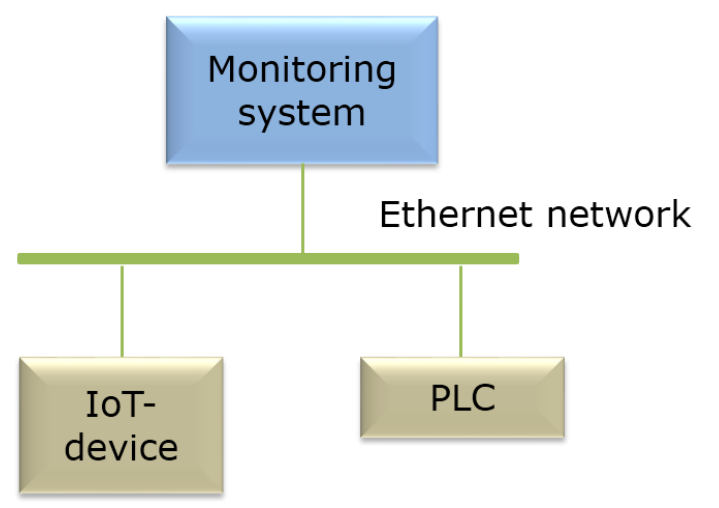

Figure 1: Block diagram of the proposed Ethernetbased monitoring system

As it is illustrated, an Ethernet network acts as backbone for data exchange between the involved nodes. On the one hand, the monitoring system is responsible of gathering operational data from the connected devices and displaying the relevant information to the user. Such information is fed in real-time with both numerical and graphical representations so the user is able to track the current status and operation of the microgrid. In addition, tasks like alarm generation and data accumulation are also performed by the monitoring system.

On the other hand, concerning hardware components, two main types of devices are considered in the proposal. PLC are commonly applied for automating processes and for data acquisition from sensors on the facility with well-known reliable operation. In the case of open-source IoT devices, they can perform the same tasks aforesaid (automation and/or data acquisition) or can be devoted to a single function. For instance, an Arduino board can be linked to a particular sensor, performing data polling and conditioning to be sent to the monitoring system through the network. On the other hand, such a device could implement some control algorithm processing measurements from sensors and commanding actuators.

Even more, the proposal can accommodate other commercial devices which are equipped with Ethernet connectivity like those devoted to energy management like photovoltaic inverters, power analysers, etc. 
The monitoring function is performed by a software environment which can run in different hardware equipment. For instance, the high-level graphical language LabVIEW, profusely used both in energyrelated facilities $[2,9,18]$ and industrial systems [1], is commonly executed in a PC. Other packages that are gaining increasing attention are those developed under the open-source philosophy, for example, Grafana [11]. This software allows designing customized dashboards with user-friendly graphs and in-built functions, being mainly devoted to UNIX operative systems, such as Raspbian which runs in RPi.

As can be observed in Figure 1, the monitoring system and the hardware equipment share information over an Ethernet network. Consequently, a requirement for the application of the proposal consists on the availability of Ethernet port (RJ45) in the devices. Besides, depending on the amount of nodes to link and on the topology, one or more Ethernet switches or routers are also needed. The sensors and/or actuators that PLC and IoT devices have connected are not included in the architecture for a clearer view of data exchange over Ethernet. Moreover, on-line remote access to the monitoring system is facilitated due to the direct connection of the Ethernet network to the Local Area Network (LAN) of the building or facility where the monitored microgrid is deployed.

In order to achieve a higher degree of generality, the proposed system does not specify the communication protocol. E.g., the nodes can share data over the Ethernet network regardless the particular protocol, for example, by means of TCP/IP, PROFINET or Modbus TCP.

\section{EXPERIMENTAL}

$\begin{array}{lrr}\text { APPLICATION } & \text { CASES } & \text { IN } \\ \text { RENEWABLE } & & \text { ENERGY } \\ \text { MICROGRIDS } & & \end{array}$

As indicated in the Introduction, a set of renewable energy-hydrogen microgrids have been designed and experimentally implemented within R\&D activities. In this section, two of these facilities are briefly described and the corresponding Ethernet-based monitoring systems are commented.

\subsection{MICROGRID WITH PLC-BASED AUTOMATION SYSTEM}

The microgrid consists on a lab-scale facility which combines PV and wind generation coupled around a low voltage DC bus. Such bus is the backbone where the electrical flows occur and is deployed by means of a lead-acid battery. In addition, the energy carrier hydrogen is included in the microgrid through equipment for generation (electrolyser) and consumption (fuel cell) interconnected using a hydrogen bus based on metal hydride bottles. An electronic programmable load is applied to demand different load profiles. The layout of this microgrid is depicted in Figure 2.

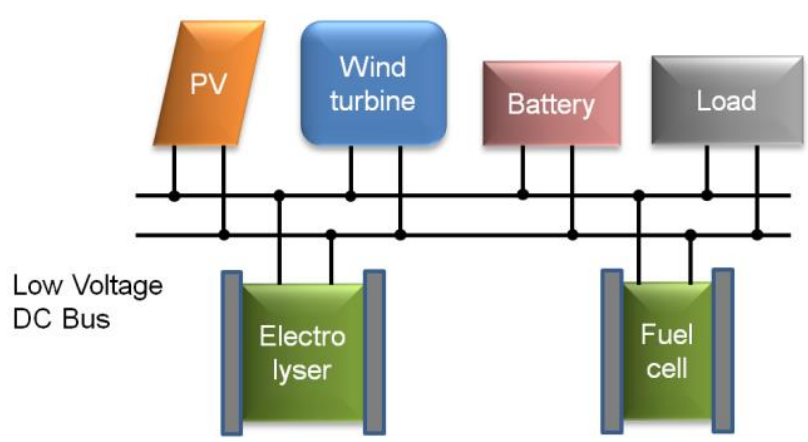

Figure 2: Schematic diagram of the microgrid in case 3.1

This microgrid is automated by a PLC (S7-300, Siemens). This controller manages the activation and deactivation of the generation/consumption equipment aiming to use the surplus of PV energy to generate hydrogen. Sensors devoted to measure voltage, current, irradiance, temperature, hydrogen flow, hydrogen pressure, etc., are the input signals of the PLC. Figure 3 shows the aspect of the main components of this microgrid in the laboratory.

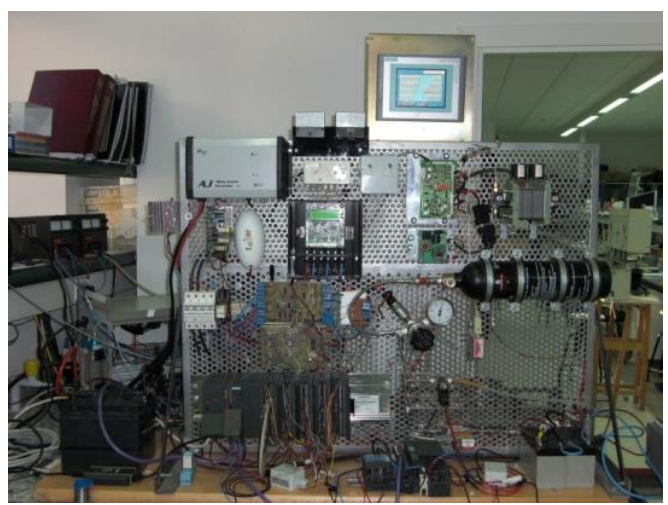

Figure 3: Aspect of the experimental setup within the laboratory.

To deploy the Ethernet-based monitoring system, a Communication Processor (CP) is used to provide Ethernet connectivity to the PLC, so it exchanges information with the monitoring software. Such monitoring task is implemented by the WinCC software of Siemens, executed in a PC. The block diagram of the developed monitoring system is depicted in Figure 4. As can be observed, data from 
the microgrid operation are exchanged through Ethernet between the PLC and the monitoring system.

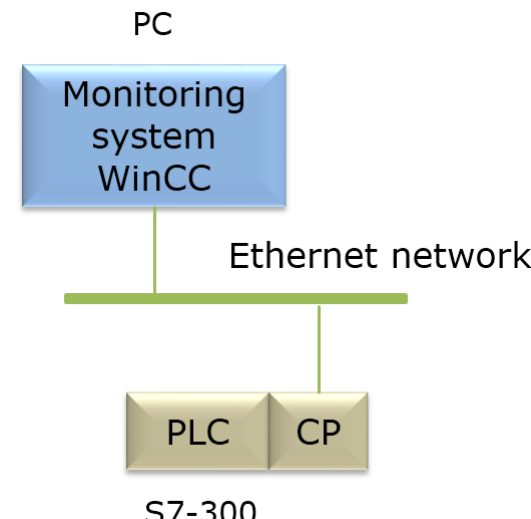

Figure 4: Deployed monitoring system based on Ethernet for application case 3.1.

Figure 5 shows a screen of the developed monitoring interface where the evolution of the voltage and current of the hydrogen generator is graphically illustrated in real-time. Further details can be found in [8].

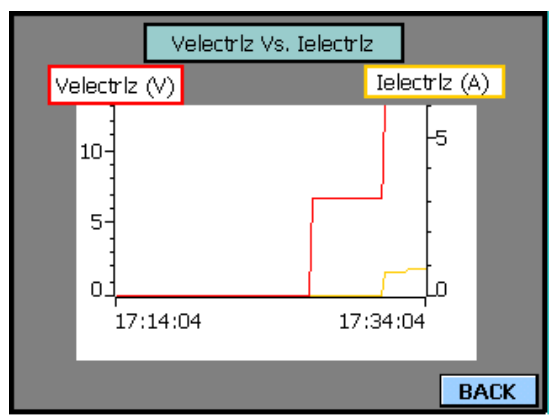

Figure 5: Monitoring interface to graphically display variables in WinCC.

\subsection{PV TEMPERATURE MONITORING USING ARDUINO AND LABVIEW}

To begin with, it must be noted that the microgrid monitored in these last application cases is the same. In other words, for this microgrid, two different monitoring systems have been orchestrated following the proposed Ethernet-based architecture in diverse stages of development. The first application is described in this subsection whereas the second one is expounded in the next subsection.

Moreover, the layout of this microgrid is very similar to the previous one (Figure 6). The main difference resides in the scale of the microgrid. E.g., in this case, the power of the associated equipment is noticeably larger than those involved in the microgrid of the previous subsection. For example, the PV generator in this case is composed by 6 modules connected to provide a total power of $1.100 \mathrm{~W}$ (Figure 7) whilst the lab-scale microgrid included two modules with a joint power of $90 \mathrm{~W}$.

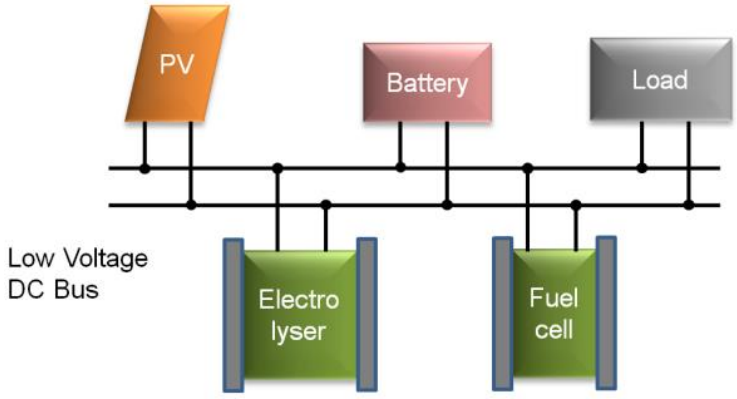

Figure 6: Schematic diagram of the microgrid in cases 3.2 and 3.3.

Another relevant aspect is that wind power is not implemented in this microgrid. The renewable energy is generated solely by means of the aforementioned PV facility. Finally, it must be remarked that the energy storage is carried out in this case by means of a Lithium-ion battery, which is a more modern technology in comparison with the lead-acid battery used in the microgrid of the case 3.1 .

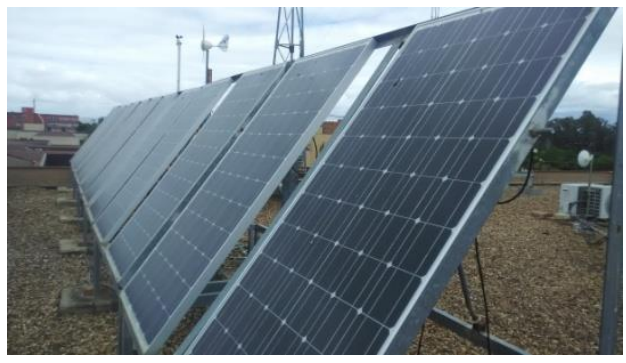

Figure 7: Aspect of the set of PV modules.

The PLC model S7-1500 of Siemens has been chosen to handle the interaction between the components as well as to acquire the relevant measurements from the physical facility.

Concerning the Ethernet-based monitoring system, the monitoring interface is designed using LabVIEW running in a PC. The operator/research is able to track the behaviour of the microgrid through the data displayed graphically and numerically by this interface. Hence, this software shares information with the PLC that automates the microgrid as well as with an Arduino board responsible of sensing tasks. Particularly, a temperature sensor Lm35 is connected to an Arduino MEGA board so the provided measurements are sent to the monitoring system via Open Platform Communications (OPC) over the Ethernet network. The architecture of the implemented monitoring system is depicted in Figure 8. In addition, Figure 9 shows the curve of the sensed 
temperature in the LabVIEW monitoring interface. For further information, refer to [9].

PC

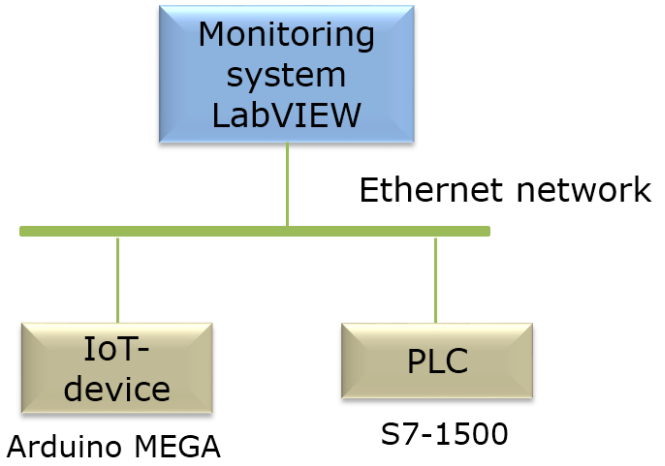

Figure 8: Deployed monitoring system based on Ethernet for application case 3.2

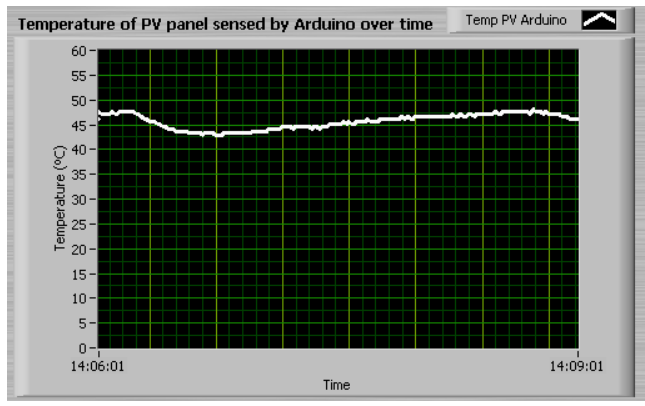

Figure 9: Graphical evolution of a PV module temperature in LabVIEW.

\subsection{MONITORING SYSTEM USING OPEN-SOURCE TECHNOLOGY}

In the present case, the open-source package Grafana is used for monitoring tasks. The remote operator accesses on-line to custom-designed interface mainly focused on time-series. This software runs in a RPi linked to an Arduino MEGA devoted to sense the temperature of the PV generator. In fact, digital temperature sensors DS18B20 are used to sense the temperature of each module of the generator.

The information retrieved by the Arduino board is exchanged with the Grafana dashboard by means of an Ethernet linkage. On the other hand, through the same Ethernet network, Modbus TCP is used to collect data from a commercial controller called Color Control GX of manufacturer Victron Energy. This device acquires signals from other equipment like the Lithium-ion battery and a solar charger with Maximum Power Point Tracking (MPPT). This way, by means of Ethernet communication, the Grafana interface provides real-time information to the operator about the microgrid operation. The described Ethernet-based architecture is illustrated in Figure 10 while in Figure 11 the temperature measurements of the PV generator are depicted in the developed Grafana dashboard. For further information, refer to [7].

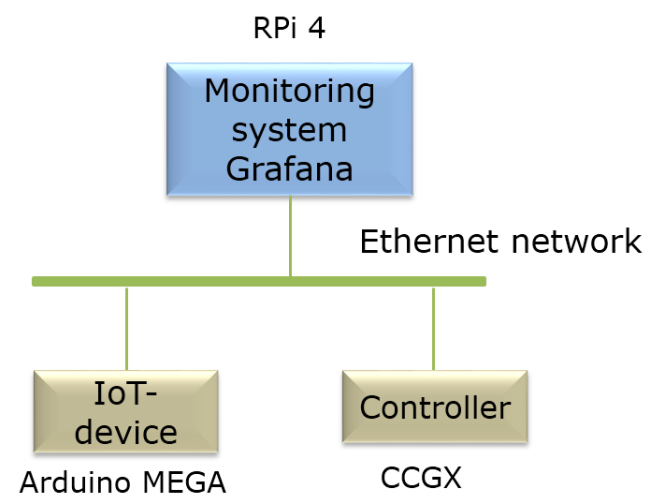

Figure 10: Deployed monitoring system based on Ethernet in application case 3.3 .

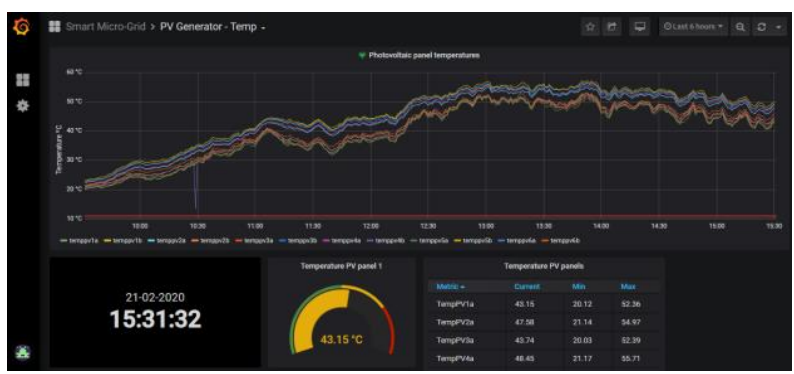

Figure 11: Monitoring interface developed to display the temperatures of PV modules in Grafana.

\section{CONCLUSIONS}

Choosing an Ethernet-based communication network is a requirement for modern advanced automated infrastructures. Particularly, the importance of data management and transmission in intelligent microgrids imposes a proper selection of communication means and standards.

The paper has presented an Ethernet-based architecture to deploy monitoring systems applied to renewable energy-hydrogen microgrids. In addition, a set of experimental application cases have been reported to validate the proposal as well as to illustrate the wide variety of hardware and software technologies that can be accommodated. In fact, both proprietary industrial control devices (PLC) and open-source IoT equipment (RPi and Arduino) can be integrated in the proposal.

The usage of Ethernet networks facilitates a seamless data exchange between most of hardware and software tools available for automation and monitoring tasks. The trend of industrial fieldbuses towards Ethernet-based networks highlights the 
relevance of this standard also for Smart Grids and Smart Microgrids.

Future guidelines include the development of digital replications of the components of the microgrid using the gathered data during mid and long-term operation.

\section{Acknowledgments}

This work has been supported by the FEDER Funds (Programa Operativo FEDER de Extremadura 20142020) through the grant "Ayuda a Grupos de Investigación" (ref. GR18159) of Junta de Extremadura.

\section{Resumen en español}

\begin{tabular}{lccc} 
SISTEMAS & DE & \multicolumn{2}{c}{ MONITORIZACIÓN } \\
BASADOS EN & ETHERNET & PARA \\
MICROGRIDS & DE & ENERGÍA \\
RENOVABLE-HIDRÓGENO
\end{tabular}

\section{Resumen}

La digitalización de los sistemas energéticos ha dado lugar a escenarios desafiantes como las Smart Grids y Microgrids. Estas infraestructuras se basan fundamentalmente en generación descentralizada así como en la gestión inteligente de los flujos de energía y comunicaciones. Para su implementación efectiva, es esencial una red de comunicaciones que permita el intercambio de datos entre la elevada cantidad de sensores, controladores y nodos de supervisión involucrados. Redes basadas en Ethernet se han convertido en el medio de comunicación prevalente en entornos de oficina y gestión, siendo cada vez más aplicadas también para instalaciones industriales. Consecuentemente, las Smart Grids y Microgrids también incorporan comunicación Ethernet. Este artículo presenta una arquitectura para sistemas de monitorización basada en Ethernet en la que el software de monitorización, dispositivos propietarios de automatización y equipos opensource comparten datos en torno a una red Ethernet. La propuesta es validada mediante un conjunto de instalaciones experimentales.

Palabras clave: Energías renovables, microgrid, Ethernet, automatización, monitorización, red de comunicaciones, IoT.

\section{References}

[1] Arpaia, P., De Matteis, E., Inglese, V., (2015) "Software for measurement automation: A review of the state of the art", Measurement, vol. 66, pp. 10-25.

[2] Calderón, A.J., González, I., Calderón, M., Segura, F., Andújar, J.M., (2016) "A New, Scalable and Low Cost Multi-Channel Monitoring System for Polymer Electrolyte Fuel Cells", Sensors, vol. 16(3), 349.

[3] Cintuglu M.H., Mohammed O.A., Akkaya K., Uluagac A.S., (2017) "A survey on smart grid cyber-physical system testbeds", IEEE Commun Surv Tutorials, vol. 19, pp.446-64.

[4] Ferreira, A., Ferreira, A., Cardin, O., Leitão, P., (2015) "Extension of holonic paradigm to smart grids", IFAC-PapersOnLine, VOL. 48(3), pp. 1099-1104. DOI: 10.1016/j.ifacol.2015.06.230.

[5] Fuentes, M., Vivar, M., Burgos, J.M., Aguilera, J., Vacas, J.A., (2014) "Design of an accurate, low-cost autonomous data logger for PV system monitoring using Arduino ${ }^{\mathrm{TM}}$ that complies with IEC standards," Solar Energy Materials \& Solar Cells, vol. 130, pp. 529-543.

[6] Gomes, L., Vale, Z., Corchado, J.M., (2020) "Microgrid management system based on a multi-agent approach: An office building pilot", Measurement, vol. 154, pp. 107427.

[7] González, I., Calderón, A.J., Portalo, J.M., (2021) "Innovative Multi-Layered Architecture for Heterogeneous Automation and Monitoring Systems: Application Case of a Photovoltaic Smart Microgrid", Sustainability, vol. 13(4), 2234. https://doi.org/10.3390/su13042234

[8] González, I., Calderón, A.J., Andújar, J.M., (2017) "Novel Remote Monitoring Platform for RES-Hydrogen based Smart Microgrid", Energy Conversion and Management, vol. 148, pp. 489-505. DOI: 10.1016/j.enconman.2017.06.031.

[9] González, I.; Calderón, A.J., (2019) "Integration of open source hardware Arduino platform in automation systems applied to Smart Grids/Micro-Grids", Sustainable Energy Technologies and Assessments, vol. 36, 100557.

[10] https://www.arduino.cc

[11] https://grafana.com/

[12] https://www.raspberrypi.org/

[13] https://www.sma-uk.com/

[14] https://www.victronenergy.com/ 
[15] IEEE standard for Ethernet: https://standards.ieee.org/standard/802_32018.html

[16] Iovev A.N., Yakimov P.I., (2015) “Application of PLC as a gateway in a network of smart power transducers", IFAC-PapersOnLine, vol. 48(24), pp. 95-8.

[17] Paredes-Parra, J.M.; Mateo-Aroca, A.; SilventeNiñirola, G.; Bueso, M.C.; Molina-García, Á., (2018), "PV Module Monitoring System Based on Low-Cost Solutions: Wireless Raspberry Application and Assessment", Energies, vol. 11, pp. 3051. DOI: 10.3390/en11113051.

[18] Pereira, R.I.S., Dupont, I.M., Carvalho, P.C.M., Jucá, S.C.S., (2018) "IoT embedded linux system based on Raspberry Pi applied to realtime cloud monitoring of a decentralized photovoltaic plant", Measurement, vol. 114, pp. 286-297.

DOI: 10.1016/j.measurement.2017.09.033.

[19] Rojas R.A., Ruiz Garcia M.A., (2020) "Implementation of Industrial Internet of Things and Cyber-Physical Systems in SMEs for Distributed and Service-Oriented Control", In: Matt D., Modrák V., Zsifkovits H. (eds) Industry 4.0 for SMEs. Palgrave Macmillan, Cham. DOI: https://doi.org/10.1007/978-3-03025425-4_3

[20] Vargas-Salgado, C., Aguila-Leon, J., ChiñasPalacios, C., Hurtado-Pérez, E., (2019), "Lowcost web-based Supervisory Control and Data Acquisition system for a microgrid testbed: A case study in design and implementation for academic and research applications", Heliyon, vol. 5 , e02474.

[21] Yang, Q., An, D., Yu,W., Tan, Z., Yang, X., (2016) "Towards Stochastic OptimizationBased Electric Vehicle Penetration in a Novel Archipelago Microgrid", Sensors, vol. 16, 907.

[22] Zhang, L., Gari, N., Hmurcik, L.V., (2014) "Energy management in a microgrid with distributed energy resources", Energy Conversion and Management, vol. 78, pp. 297305.

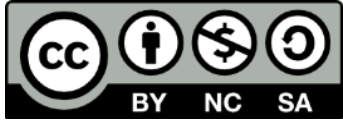

(C) 2021 by the authors. Submitted for possible open access publication under the terms and conditions of the Creative Commons Attribution CC BY-NC-SA 4.0 license 